\title{
Spillover from marine reserves and the replenishment of fished stocks
}

\author{
BENJAMIN S. HALPERN ${ }^{1 *}$, SARAH E. LESTER ${ }^{2}$ AND JULIE B. KELLNER ${ }^{3,4}$ \\ ${ }^{1}$ National Center for Ecological Analysis and Synthesis, 735 State Street, Santa Barbara CA 93101, USA, ${ }^{2}$ Marine Science Institute, University of \\ California, Santa Barbara CA 93106, USA, ${ }^{3}$ Department of Environmental Science and Policy, University of California, Davis CA 95616, USA, \\ and ${ }^{4}$ Biology Department, Woods Hole Oceanographic Institution, MS\#34, Woods Hole MA 02543, USA
}

Date submitted: 12 October 2009; Date accepted: 13 December 2009; First published online: 24 February 2010

\section{SUMMARY}

No-take marine reserves are widely recognized as an effective conservation tool for protecting marine resources. Despite considerable empirical evidence that abundance and biomass of fished species increase within marine reserve boundaries, the potential for reserves to provide fisheries and conservation benefits to adjacent waters remains heavily debated. This paper uses statistical and population models to evaluate published empirical data on adult spillover from marine reserves and shows that spillover is a common phenomenon for species that respond positively to reserve protection, but at relatively small scales, detectable on average up to $800 \mathrm{~m}$ from reserve boundaries. At these small scales, local fisheries around reserves were likely unsustainable in 12 of 14 cases without the reserve, and spillover partially or fully offsets losses in catch due to reserve closure in the other two cases. For reserves to play a role in sustaining and replenishing larger-scale fished stocks, networks of reserves may be necessary, but as few exist this is difficult to evaluate. The results suggest reserves can simultaneously meet conservation objectives and benefit local fisheries adjacent to their boundaries.

Keymords: adult fish movement, fisheries, global, marine protected areas, no-take reserves, spillover effect, synthesis

\section{INTRODUCTION}

Widespread concern exists over the health of marine ecosystems given the diversity and impact of human activities affecting these systems worldwide (Halpern et al. 2008), with overfishing consistently identified as a key threat to all parts of the world's oceans (Pauly et al. 1998). Overexploitation has resulted in dire predictions about the ability of oceans to continue supporting fisheries (Worm et al. 2006), in turn leading to calls for fishery management reform (Costello et al. 2008) and increased protection to maintain some locations in a more 'pristine' ecosystem state (Lubchenco et al. 2003). Notake marine reserves, which prohibit all exploitative activities, have become widely recognized as an effective conservation

\footnotetext{
*Correspondence: Dr Benjamin S. Halpern Tel: +1 8058922531
}

Fax: +1 8058922510 e-mail: halpern@nceas.ucsb.edu tool for protecting marine resources, resulting in increases in the abundance, biomass and diversity of many species within their boundaries (Halpern 2003; Micheli et al. 2004; Lester et al. 2009). However, the ability for reserves to provide conservation or fisheries benefits to adjacent waters remains highly controversial (Roberts et al. 2001; Tupper 2002; Gell \& Roberts 2003; Hilborn et al. 2004).

Growing evidence from theoretical models and empirical studies suggests that higher abundances inside reserves can lead to spillover of adults to nearby fished areas (Rowley 1994; Roberts et al. 2001; Goni et al. 2008; Kellner et al. 2008; Perez-Ruzafa et al. 2008). Spillover is typically observed as declining patterns of abundance or catch across reserve boundaries, although there may be no detectable pattern of decline in abundance if fishing effort is intense surrounding the reserve. Additional evidence comes from ecosystem-level models evaluating the effect of large closures on fish stocks and landings (for example see Guenette et al. 2000; Pitcher et al. 2002; Zeller \& Reinert 2004), measures of changing fisheries yield or profit adjacent to reserves (McClanahan \& Mangi 2001; Alcala et al. 2005; Abesamis et al. 2006a) and from studies of small-scale adult movement patterns across reserve boundaries (Samoilys 1997; Zeller et al. 2003; Topping et al. 2005). However, these studies cannot address the extent to which small-scale reserves may benefit local fishers (in the case of the ecosystem-level models) or determine if reserves can benefit local fish stocks and fishery catches (in the case of the adult movement studies). A recent study used a spatiallyexplicit population growth and harvest model to simulate potential spillover rates and distances, a key step towards addressing the nature of spillover (Perez-Ruzafa et al. 2008). The critical next step is to tie such models to empirical data on spillover and assess whether reserves are generally expected to compensate local fisheries for lost yields due to fishing displacement from reserves. Answering this question could prove crucial in resolving debates about reserve establishment (Hilborn et al. 2004; Roberts et al. 2005). If this compensation does occur, even if only partially, then no-take reserves can play a key role in fisheries management, as well as conservation.

Here we synthesize empirical evidence of adult spillover to address four fundamental questions about the nature and extent of spillover from marine reserves. (1) How common is spillover for those species that respond positively to reserve protection? (2) How far from reserves can spillover be detected? (3) Do traits of species (i.e. mobility) or reserves (i.e. size or age) influence spillover occurrence and detectable 


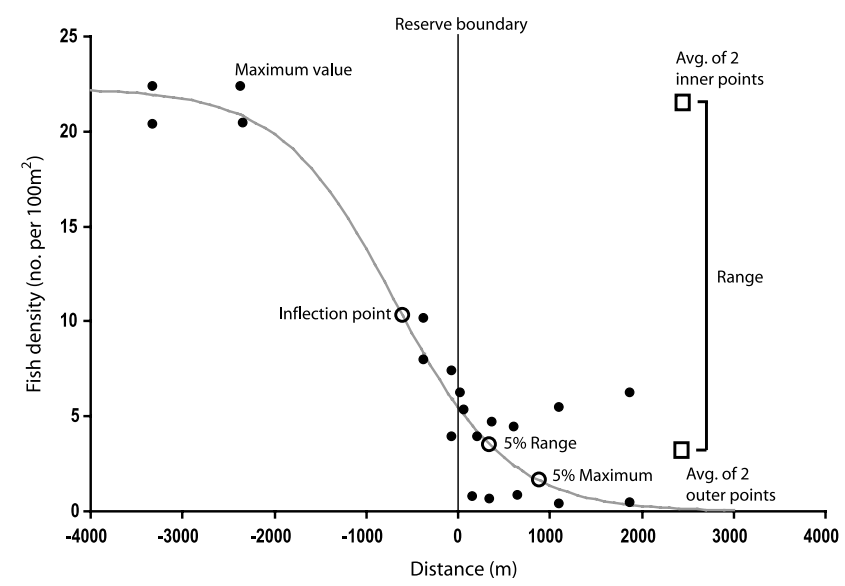

Figure 1 Metrics for estimating spillover distance (see Methods) applied to a sample dataset (Guidetti 2007) for which the logistic curve was the best fit (see Appendix 1, supplementary material at URL http://www.ncl.ac.uk/icef/EC_Supplement.htm).

distance? (4) Does spillover compensate fishers for catch lost to closed fishing grounds and, if so, to what extent? We employ a two-pronged approach to address these questions. First, we use statistical models and a variety of metrics to assess the nature and extent of spillover (Fig. 1). Second, we use these results to fit a reaction-diffusion model that estimates spillover rate at each reserve and determines whether fishery catch would be locally sustainable without the reserve in place. While spatially-explicit reaction-diffusion models have a long history in conservation applications (Shigesada \& Kawasaki 1997; Cantrell \& Cosner 2003), this is an innovative use of this type of model, particularly in combination with statistical analyses of empirical data. Combining these two approaches provides a novel assessment of whether reserves compensate, or even enhance, local catch via spillover.

\section{METHODS}

\section{Synthesis}

We synthesized all studies published in the literature prior to March 2009 containing spatially-explicit empirical data of spillover from no-take marine reserves identified from searches of Web of Science using the keywords 'marine reserve', 'spillover' or 'marine protected area'. We found independent measures of overall spillover from 16 reservelevel surveys and 35 taxonomic groups (species, genus or family level) from those reserves (Appendices 1-3, see supplementary material at URL http://www.ncl.ac.uk/icef/ EC_Supplement.htm). We did not include adult movement data because these studies examine individuals rather than abundances and our focus was on population-level outcomes of individual movements. We also did not include data from areas with partial protection to avoid confounding results with protection status. We obtained data from figures, tables or the authors on abundance, biomass or catch at increasing distances in each direction from the reserve centre to areas outside the reserve (if more than one direction was surveyed, i.e. 'transects') and for each taxonomic group separately. Measurements at four or more distances within and around a reserve from each study were required for model fitting. Relevant papers that we excluded because they did not meet our criteria are addressed in the Discussion. To assess reservelevel spillover, we used data reported at the reserve level when provided and otherwise combined data from individual taxonomic groups and transects at a reserve. We recorded reserve size and age from each study, and species mobility (whether sedentary, mobile or highly mobile) from FishBase (see URL http://www.fishbase.org).

In four cases, the original research reported two different metrics for spillover (Appendix 1, see supplementary material at URL http://www.ncl.ac.uk/icef/EC_Supplement. $\mathrm{htm}$, 'measured responses' column, for example density and catch). We used the following decision rules to select the most appropriate measure to include in our synthesis (Appendix 1, see supplementary material at URL http://www.ncl.ac.uk/ icef/EC_Supplement.htm, measure used). For Apo Reserve (Abesamis et al. 2006b), we used density for reserve level analyses because it was the only measure available, but used biomass for taxonomic analyses because biomass is the more relevant metric when evaluating fisheries compensation. Spillover distance estimates at the taxonomic level were nearly identical for density versus biomass for this study, so this decision had no effect on our results. For Mombasa Reserve (McClanahan \& Mangi 2000), we used catch rather than mean fish size data, because mean size masks abundance and/or biomass patterns while catch is a direct measure of fisheries benefit. For Barbados Reserve (Rakitin \& Kramer 1996), we used catch rather than density data as density gradients do not always reflect true spillover patterns (as discussed below), but we report both measures in Appendix 1 (see supplementary material at URL http://www.ncl.ac.uk/ icef/EC_Supplement.htm) to help illustrate this point. Finally, for Columbretes Reserve (Goni et al. 2006), we used catch per unit effort (CPUE) rather than catch per unit area (CPUA) data because the former were measured both inside and outside the reserve while the latter were only measured outside the reserve, and thus model fits were more accurate (and conservative) with CPUE data.

\section{Statistical models of potential spillover}

The expectation that spillover from marine reserves will produce abundance gradients with distance from the reserve, with a shape that depends on species mobility and catch rates, was first described over a decade ago (Rakitin \& Kramer 1996) and later refined and modelled (Kaunda-Arara \& Rose 2004; Goni et al. 2006). We expanded on these previous modelfitting approaches and estimated spillover by fitting three model forms (exponential decay, Eq. 1; linear decay, Eq. 2; and logistic decay, Eq. 3) to each dataset, all of which imply the same mechanism and essentially capture different parts of 
a logistic curve, in order to find the best fit to the empirical data.

$$
\begin{aligned}
& Y=\exp (\alpha \times x) \\
& Y=\alpha \times x+\beta \\
& Y=\alpha /(1+\beta(\exp (\delta \times x)))
\end{aligned}
$$

where $Y$ is adult abundance (or catch) and $x$ is the distance from the reserve boundary (negative values are inside the reserve). For Eqs (1) and (2), $\alpha$ estimates the rate of decline in spillover, while in Eq. (3) $\alpha$ is the magnitude of the reserve effect (i.e. how much a variable, such as density, changes due to protection provided by a no-take reserve), $\beta$ is where the midpoint of the diminishing reserve effect is centred (this 'inflection point' is inside the reserve if $\beta>1$, outside the reserve if $\beta<1$, and centred on the reserve boundary if $\beta=1$ ) and $\delta$ is how steeply the reserve effect declines (larger values of $\delta$ represent steeper declines). In Eq. (3), the combination of $\beta$ and $\delta$ determine how far spillover spreads beyond the reserve boundary, with the expectation that both parameters are affected by species' mobility and the intensity and spatial pattern of fishing outside the reserve. The use of multiple models allowed us to find the best fit to the empirical data while not requiring that the sampling assumptions for the logistic fit hold true. In cases where the logistic decay fit was computationally possible but produced negative values for $\beta$ (which produces a curve that is no longer logistic), spillover distances were calculated using the next best fit model.

Model fits were conducted using the nls function in $\mathrm{R}$ ( $\mathrm{R}$ 2006), which seeds the fitting procedure with chosen parameter values and then searches for those that produce the best fit. In every case but one transect, both linear and exponential functions were fit, while for eight reservelevel and nearly half of the taxonomic-level datasets, logistic functions could not be fit. This is expected because spatiallyexplicit monitoring data are often not sufficient to capture the full spatial pattern, especially when there are limited sampling sites within the reserve. In these last cases, seed values across many orders of magnitude were tested, but the data were either too sparse or too variable to allow for logistic model fitting. We used an Akaike information criterion (AIC) model selection procedure to compare model fits.

Past studies have primarily calculated the inflection point of logistic fits to estimate spillover distance (Kaunda-Arara \& Rose 2004; Abesamis et al. 2006b), but this method captures the midpoint, not the detectable extent, of spillover. Therefore, we developed several new methods that better capture detectable spillover distance (Fig. 1). For all three model forms, we calculated the distance at which the curve is $5 \%$ of the maximum observed value and $5 \%$ of the observed range. The range is defined as the average of the two points furthest outside the reserve to the average of the two points furthest inside the reserve. These two metrics provide a conservative (5\% range) and more liberal (5\% maximum) estimate of how far outside the reserve spillover can be detected. For logistic fits, we also calculated where the inflection point occurs for comparison with previous methods (Appendix 2, see supplementary material at URL http:// www.ncl.ac.uk/icef/EC_Supplement.htm). Spillover distances can be negative (i.e. inside reserve boundaries), in which case fishing impacts reach further into the reserve than target species spill out. We also tested whether spillover distance was affected by reserve size, number of years of protection at time of survey and species mobility (sedentary versus mobile) using a multivariate linear model (R 2006).

\section{Population models (reaction-diffusion models)}

Of the 35 taxonomic datasets we evaluated, 17 included a logistic decay statistical model as a best fit (Appendix 2, see supplementary material at URL http://www.ncl.ac. uk/icef/EC_Supplement.htm). These data come from eight of the 13 reserves evaluated in our analyses. For these datasets, we calculated the best-fit reaction-diffusion model to the logistical model to assess whether the local fisheries would be viable without the reserve and, if so, to what extent lost catches due to reserve creation were compensated for by potential increases in catch outside the reserve.

For the population modelling framework, we used a Fisher reaction-diffusion model (Fisher 1937), which includes logistic growth, combined with a linear catcheffort production function. Kellner et al. $(2007,2008)$ and Perez-Rusafa et al. (2008) have previously shown that this form of a reaction-diffusion model produces the sigmoid shaped spillover curves exhibited across many marine reserve boundaries. Accordingly, population density, $n$, is described at each point in space as follows:

$$
\begin{aligned}
\frac{\partial n}{\partial \tilde{t}}= & \tilde{D}\left(\frac{\partial^{2} n}{\partial x^{2}}\right)+n\left(1-\frac{n}{k}\right)-\tilde{f} n \\
& \text { where } \tilde{t}=r t, \tilde{D}=D / r, \tilde{f}=f / r
\end{aligned}
$$

where the rate of movement $(\tilde{D})$, fishing $(\tilde{f})$ and time are scaled to the population growth rate $(r)$ to reduce the number of parameters needed for the least-squares fit, and $k$ is the maximum density. The scaled fishing rate was set to zero inside the reserve $(\tilde{f}=0)$. We also assumed no losses at the region edges (i.e. reflecting boundaries $\frac{\partial n}{\partial x}=0$ ). Otherwise all parameters were considered homogeneous across space, including the fishing rate outside the reserve (we address the implications of this assumption in the Discussion).

Like the statistical model analysis, the parameters were estimated using least squares to find the best-fit reactiondiffusion model at equilibrium that approximates the logistic curve derived in the statistical analysis above. This method for parameter estimation provides the most consistency across the empirical studies examined here given the paucity of movement and demographic data available for most marine 
species. The reaction-diffusion model produced reasonable model fits for 14 of the 17 taxonomic datasets analysed. We report the results when the reaction-diffusion model fit the logistic model with an $\mathrm{R}^{2}>0.5(n=12)$ or when the fit to the raw data was very high $\left(\mathrm{R}^{2}>0.75\right)$ despite a logistic model not emerging as a best fit for the statistical model $(n=2)$. In the two cases in which taxonomic groups were measured in two different transects, the reaction-diffusion model was fit to each transect and catch compensation estimated separately. The results were similar for both transects and are reported here as single averaged estimates of compensation.

We then integrated the relative fishing effort $(\tilde{f})$ and catch $(\tilde{c}=\tilde{f} n)$ estimates across the fished area to calculate total effort $(\tilde{F})$ and total catch $(\tilde{C})$ with the reserve in place. In order to determine population viability without a reserve, our estimates were then included in a model that removed the reserve and spread fishing effort across the entire area (i.e. $\tilde{F}$ remained constant but was spread over a larger area):

$$
\frac{\partial n}{\partial \tilde{t}}=\tilde{D}\left(\frac{\partial^{2} n}{\partial x^{2}}\right)+n\left(1-\frac{n}{k}\right)-\frac{\tilde{F}}{L} n
$$

where $L$ is the total area with the reserve now removed, such that $\tilde{F} / L<\tilde{f}$. $L$ is based on the width of the reserve boundary to the centre of the reserve plus the total distance measured outside the reserve in each study (Appendix 1, see supplementary material at URL http://www.ncl.ac.uk/icef/ EC_Supplement.htm). In this no reserve case, total catch, $\tilde{C}_{\text {NoReserve }}$, is calculated by integrating $\tilde{c}=(\tilde{F} / L) n$ across the entire region.

When a reserve is in place, spillover can often sustain fishing even if $\tilde{f}>1$ outside the reserve (i.e. fishing outside the reserve is greater than the population growth rate, see terms for reserve and regional population persistence in Kellner et al. 2007). However, the population can no longer be self-sustainable without a reserve if the fishing rate per area, $\tilde{F} / L$, is greater 1 . We used the relative estimates from the reaction-diffusion model fitting to determine whether the population could be self-sustainable without a reserve (i.e. $\tilde{F} / L<1$ ) and whether the reserve was likely to provide fisheries compensation $(\tilde{C}>$ $\left.\tilde{C}_{\text {NoReserve }}\right)$. Finally, for those cases where the local fishery is not self-sustainable without a reserve in place, we calculated the percent decrease in fishing mortality necessary to make the fishery sustainable (Table 1). All analyses were conducted in MATLAB (v6.5) and FEMLAB (v3.0).

\section{RESULTS}

Abundance of target species was higher inside no-take reserves versus areas outside for all studies included in our synthesis, and thus statistical model fits for spillover all had negative slopes. We found significant spillover from reserves based on data at the reserve level pooled across taxonomy (Fig. 2a; t-test: $\mathrm{df}=15, \mathrm{t}=2.25, p=0.04$ ) and data divided by taxonomy (Fig. $2 b$; t-test: $\mathrm{df}=34$, $\mathrm{t}=3.75, p=0.0007)$, with nearly every reserve showing positive spillover, even from very small reserves (e.g. Balicasag Reserve, $0.08 \mathrm{~km}^{2}$ ). Using the most conservative estimate (5\% range), spillover is detectable on average up to $600 \mathrm{~m}$ (reserve level) and $800 \mathrm{~m}$ (taxonomic level) from the reserve boundary, and may be detectable as far as $1500 \mathrm{~m}$ from the boundary on average based on a less conservative estimate $(5 \%$ maximum; Fig. 2 and Appendix 2, see supplementary material at URL http//www.ncl.ac.uk/icef/EC_Supplement.htm). These distance estimates are robust to the type of statistical model used (in studies for which multiple fits were selected by AIC methods; Appendix 2, see supplementary material at URL http://www.ncl.ac.uk/icef/EC_Supplement.htm) and are very similar to those found in model simulations (Perez-Ruzafa et al. 2008). Spillover distance was not affected by reserve size, years of protection or species mobility (Appendix 3, see supplementary material at URL http://www.ncl.ac.uk/icef/EC_Supplement.htm).

Reaction-diffusion model results showed that in $86 \%(12$ of 14) of the cases spillover from reserves replenished local fish catch (i.e. fishing effort was high enough that without a reserve in place the local fishery would likely be unsustainable; i.e. $\tilde{F} / L>1$; Table 1$)$. In the remaining two cases where the local fishery would be viable without the reserve $(\tilde{F} / L<$ $1)$, estimated spillover rates show that the reserve can fully compensate displaced fishers for lost local yield for one case ( $\left.\tilde{C}>\tilde{C}_{\text {NoReserve }}\right)$ and partially compensate them in the other case $\left(\tilde{C}<\tilde{C}_{\text {NoReserve }}\right)$.

\section{DISCUSSION}

Even limited spillover creates the opportunity for fishers to catch those fish, suggesting that no-take marine reserves will generally provide at least some compensation to fishers displaced by reserves. Our estimates of spillover distance are consistent with studies of large-scale partial-protection marine protected areas that find even greater spillover distances (Murawski et al. 2005), with studies of adult movement patterns showing similar or greater distances of movement across reserve boundaries (for example (Samoilys 1997; Kelly \& MacDiarmid 2003; Topping et al. 2005), and with estimates from spillover studies that did not meet our inclusion criteria (Abesamis \& Russ 2005; Goni et al. 2008; Harmelin-Vivien et al. 2008; Williams et al. 2009). However, in all of these cases, spillover acts at relatively small scales such that single reserves cannot sustain entire fished stocks (through spillover alone; they may be able to provide this service through larval export).

We may underestimate spillover distances because most empirical studies measured gradients in fish abundance rather than catch, and therefore measure detectable rather than actual spillover. In heavily fished areas, or areas where fishers concentrate their effort at reserve boundaries and 'fish-the-line', abundance patterns may show an immediate decline (Kellner et al. 2007) which could be misinterpreted as lack of spillover, while catch data would strongly indicate 
Table 1. Reaction-diffusion model fits evaluating the extent to which spillover from reserves compensates fishers for lost fishing grounds and the reduction in fishing effort required to make the fishery sustainable in the absence of the reserve.

\begin{tabular}{|c|c|c|c|c|}
\hline Reserve & Taxonomic group & $\begin{array}{l}\text { Effect of spillover on } \\
\text { fishery adjacent to reserve }\end{array}$ & $\begin{array}{l}\text { Reduction in } \tilde{F} \text { for } \\
\text { sustainability }\end{array}$ & Reference \\
\hline Torre Guaceto & Diplodus spp. & $\begin{array}{l}\text { Fishery unsustainable } \\
\text { without reserve }\end{array}$ & $>50 \%$ & (Guidetti 2007) \\
\hline Apo & Sedentary target spp. & $\begin{array}{c}\text { Catch lower with reserve; } \\
24 \% \text { compensation }\end{array}$ & none & (Abesamis et al. 2006a) \\
\hline \multirow[t]{2}{*}{ Watamu } & Siganus sutor & $\begin{array}{l}\text { Fishery unsustainable } \\
\text { without reserve }\end{array}$ & $>75 \%$ & (Kaunda-Arara \& Rose 2004) \\
\hline & Lethrinus miniatus & $\begin{array}{l}\text { Fishery unsustainable } \\
\text { without reserve }\end{array}$ & $>75 \%$ & \\
\hline \multirow[t]{2}{*}{ Malindi } & Lethrinus mahsena & $\begin{array}{l}\text { Fishery unsustainable } \\
\text { without reserve }\end{array}$ & $>75 \%$ & (Kaunda-Arara \& Rose 2004) \\
\hline & Siganus sutor & $\begin{array}{l}\text { Fishery unsustainable } \\
\text { without reserve }\end{array}$ & $>25 \%$ & \\
\hline Barbados & all target spp. & $\begin{array}{l}\text { Catch higher with reserve; } \\
135 \% \text { compensation }\end{array}$ & none & (Rakitin \& Kramer 1996) \\
\hline Columbretes Islands & Palinurus elephas & $\begin{array}{l}\text { Fishery unsustainable } \\
\text { without reserve }\end{array}$ & $>75 \%$ & (Goni et al. 2006) \\
\hline Apo & Nase vlamingii & $\begin{array}{l}\text { Fishery unsustainable } \\
\text { without reserve }\end{array}$ & $<25 \%$ & (Abesamis \& Russ 2005) \\
\hline Apo & Acanthuridae \& Carangidae & $\begin{array}{l}\text { Fishery unsustainable } \\
\text { without reserve }\end{array}$ & $>25 \%$ & (Russ et al. 2004) \\
\hline \multirow[t]{3}{*}{ South El Ghargana } & Lethrinidae & $\begin{array}{l}\text { Fishery unsustainable } \\
\text { without reserve }\end{array}$ & $>75 \%$ & (Ashworth \& Ormond 2005) \\
\hline & Serranidae & $\begin{array}{l}\text { Fishery unsustainable } \\
\text { without reserve }\end{array}$ & $>25 \%$ & \\
\hline & Scaridae & $\begin{array}{l}\text { Fishery unsustainable } \\
\text { without reserve }\end{array}$ & $>75 \%$ & \\
\hline Catalina MLR & Semicossyphus pulcher & $\begin{array}{l}\text { Fishery unsustainable } \\
\text { without reserve }\end{array}$ & $>75 \%$ & (Kellner et al. 2007) \\
\hline
\end{tabular}

otherwise. Indeed, the one study that measured both catch and abundance (Rakitin \& Kramer 1996) produced much higher spillover distances using catch data (Appendix 2, see supplementary material at URL http://www.ncl.ac.uk/icef/ EC_Supplement.htm), suggesting that detectable spillover distance may be strongly tied to the distribution and magnitude of fishing effort outside reserves. Future analyses would benefit from including both abundance and CPUE measurements in field monitoring near reserve boundaries.

Spillover is predicted to increase with reserve effect, since larger increases in abundance within reserves should lead to greater spillover. Reserve effects may (Claudet $e t$ al. 2008) or may not (Halpern 2003) increase with increasing reserve size; regardless, the reserves in our dataset were relatively small $\left(6.9 \mathrm{~km}^{2} \pm 1.7 \mathrm{SE}\right)$, limiting our ability to detect a reserve size effect on spillover distance. Reserve effect is also expected to increase with greater years of protection (Russ et al. 2004); because reserves in this study had all been protected for a relatively long time (16.1 yrs $\pm 1.8 \mathrm{SE})$ there was probably insufficient variation in age to detect a potential effect. Spillover distances did not differ by species mobility, contrary to theoretical predictions (Kellner et al. 2007) and empirical evidence from movement studies (Zeller et al. 2003; Abesamis et al. 2006b). However, our analysis lacked power because most of the species that were studied were in the same mobility category (mobile). Low sample size for highly-mobile species precluded their inclusion in analysis, but these species are not generally the focus of marine reserve goals (Le Quesne \& Codling 2009) because they may be less likely to benefit from protection except in very large reserves.

The reaction-diffusion model results provide compelling evidence that reserves can play a key role in the replenishment of the fisheries beyond their borders, at the scale of the size of the reserve, in particular when fishing pressure is high outside the reserve (or before the reserve is put in place). Indeed, without reserves, fishing effort would need to be reduced by $>50 \%$ in most cases to make the local fisheries sustainable (Table 1). The degree to which larger networks of no-take reserves could compensate fisheries at the scale of entire stocks remains an open question, although theoretical work suggests such compensation is possible (Hastings \& Botsford 1999; Neubert 2003; Kaplan \& Botsford 2005).

However, the ability of reserves to replenish fish catches does not necessarily translate into economic compensation. Fishers may have to travel greater distances (at greater cost) or fish less often owing to displacement from their original fishing grounds. Spillover may also take time to accrue, exacting short-term costs on fishers (Smith \& Wilen 2003). However, 

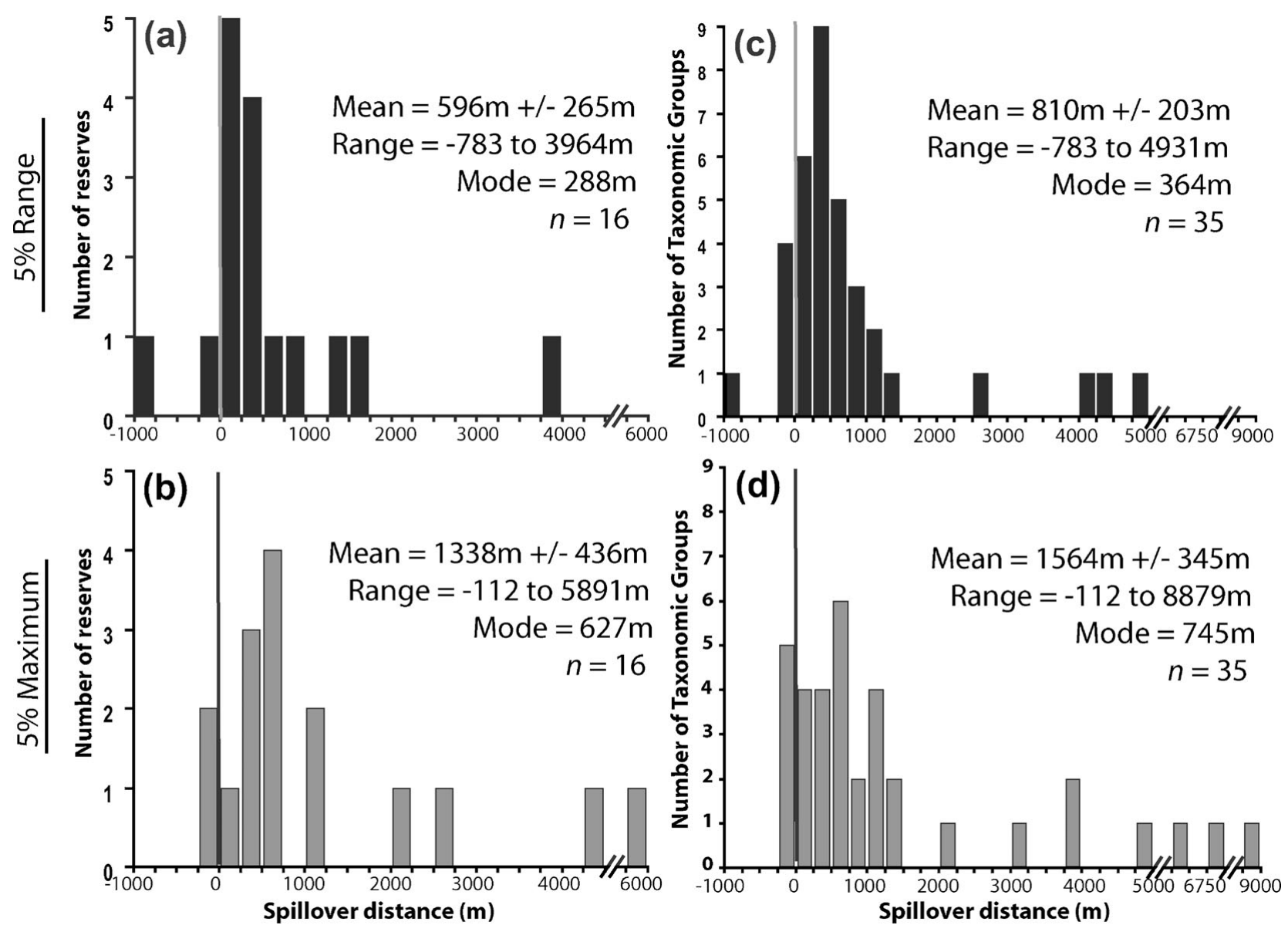

Figure 2 Histogram of spillover distances for $(a, b)$ data pooled across species and $(c, d)$ separated by species groups for $(a, c$; black histogram bars) the $5 \%$ range spillover metric and ( $b, d$; grey histogram bars) $5 \%$ maximum spillover metric. Distances were derived by selecting the best model fit for the empirical data. The thin vertical line indicates the location of the reserve boundary, with negative numbers indicating negative spillover distances.

studies that have focused on catch metrics (effort and value) support our finding that spillover can compensate fishers (Roberts et al. 2001; Murawski et al. 2005). Furthermore, our assumption that fishing effort remains constant when redistributed over the entire sampled area when the reserve is hypothetically removed may not be realistic, and influences our estimates of the sustainability of the fishery without the reserve. A reserve may also attract fishers to its borders to take advantage of spillover, and if some of those fishers come from outside the sampled area our results may under-predict catch.

Non-targeted and/or less mobile species are generally not expected to show a spillover pattern in abundance and are therefore less likely to be the focus of spillover studies. As such, we recognize that a study bias may exist in the marine reserve literature towards species that are targeted and have moderate mobility as adults (although several studies synthesized here included non-target and/or immobile species, which, as expected, showed no spillover). Given that the focus of debate about spillover and fisheries compensation is directed at targeted species, we suggest our results are robust because: (1) our quantitative methods can detect negative spillover distances, (2) we find highly consistent occurrence of spillover (14 of 16 reserves; 30 of 35 taxonomic groups) and (3) we focus on species that are targets of fisheries. Finally, spillover estimates may be spurious if underlying habitat heterogeneity instead drives abundance patterns. However, there is no evidence that reserves are sited in better habitat (Halpern et al. 2004; Lester et al. 2009), although there is evidence that spillover is facilitated by habitat continuity across reserve boundaries (Forcada et al. 2009). Furthermore, habitat protection provided by a reserve could actually decrease the potential for spillover if habitat quality drives abundance patterns and therefore fish preferentially remain inside the reserve (Rodwell et al. 2003; Forcada et al. 2008).

These results suggest how methodology may be improved for future research to ensure that questions about spillover distance and fisheries compensation can be better answered. Sampling needs to be sufficient to allow the detection of small-scale changes in fish and fishing effort inside and outside the reserve (for example every 100-250 m), and ideally include more than 10 measurements across space to allow for better model fitting. Furthermore, when possible, CPUE data should be measured, with catch data followed 
by abundance data as the next best options. If CPUE data cannot be collected, some estimate of the spatial pattern and intensity of fishing effort outside the reserve is useful, as are data on habitat distribution and quality. Distance between sampling locations should be significantly smaller than the average home-range size of the species being surveyed, and data should be collected at the centre of the reserve and at a large distance outside the reserve to provide estimates of unfished abundance and fished abundance outside the influence of spillover, respectively. Finally, data on baseline conditions before reserve establishment are helpful (FranciniFilho \& Moura 2008), but obtaining such data is challenging and should not limit future reserve studies.

Our results also provide guidelines for incorporating marine reserves into local-scale fisheries management. Networks of small- to medium-sized reserves that are large enough to protect mobile species within their boundaries, as have been recently established in California and the Great Barrier Reef, are probably preferable to larger fewer reserves, as adult spillover is a relatively small-scale phenomenon. This confirms previous theoretical predictions on the design of reserve networks for fisheries management (Neubert 2003) and recommendations reached from model simulations of spillover effects (Perez-Ruzafa et al. 2008). Additionally, because reserves are likely to compensate local fishers for lost catch (although perhaps not lost profit), especially in intensely fished systems, those fishers who are displaced by a reserve will be the same ones who directly benefit from spillover. Whether or not they are fully compensated economically, and how quickly such compensation could happen, remains an open research question, but our results suggest marine reserves can locally replenish fish stocks outside their boundaries. Therefore, no-take marine reserves need not create conflict between fishery and conservation goals, and, in fact, may often offer a solution benefiting all parties.

\section{ACKNOWLEDGEMENTS}

We thank R. Goni for sharing data, and S. Gaines, M. Baskett, A. Hastings, D. Kramer and an anonymous reviewer for helpful comments on the paper. Support was provided by a grant from the David and Lucille Packard Foundation to NCEAS for ecosystem-based management of marine systems, the Partnership for Interdisciplinary Studies of Coastal Oceans (PISCO) funded by the David and Lucile Packard Foundation and the Gordon and Betty Moore Foundation (contribution number 348), the Sustainable Fisheries Group supported by the Paul G. Allen Family Foundation and the Bahamas Biocomplexity Project (US NSF Biocomplexity grant OCE-0119976) and US EPA Science to Achieve Results (R832223).

\section{References}

Abesamis, R.A. \& Russ, G.R. (2005) Density-dependent spillover from a marine reserve: long-term evidence. Ecological Applications 15(5): 1798-1812.
Abesamis, R.A., Alcala, A.C. \& Russ, G.R. (2006a) How much does the fishery at Apo Island benefit from spillover of adult fish from the adjacent marine reserve? Fishery Bulletin 104(3): 360-375.

Abesamis, R.A., Russ, G.R. \& Alcala, A.C. (2006 $b$ ) Gradients of abundance of fish across no-take marine reserve boundaries: evidence from Philippine coral reefs. Aquatic Conservation: Marine and Freshmater Ecosystems 16(4): 349-371.

Alcala, A.C., Russ, G.R., Maypa, A.P. \& Calumpong, H.P. (2005) A long-term, spatially replicated experimental test of the effect of marine reserves on local fish yields. Canadian Fournal of Fisheries and Aquatic Sciences 62(1): 98-108.

Ashworth, J.S. \& Ormond, R.F.G. (2005) Effects of fishing pressure and trophic group on abundance and spillover across boundaries of a no-take zone. Biological Conservation 121(3): 333-344.

Cantrell, R.S. \& Cosner, C. (2003) Spatial Ecology via Reactiondiffusion Equations. New York, NY, USA: John Wiley and Sons.

Claudet, J., Osenberg, C.W., Benedetti-Cecchi, L., Domenici, P., Garcia-Charton, J.A., Perez-Ruzafa, A., Badalamenti, F., Bayle-Sempere, J., Brito, A., Bulleri, F., Culioli, J.M., Dimech, M., Falcon, J. M., Guala, I., Milazzo, M., Sanchez-Meca, J., Somerfield, P.J., Stobart, B., Vandeperre, F., Valle, C. \& Planes, S. (2008) Marine reserves: size and age do matter. Ecology Letters 11(5): 481-489.

Costello, C., Gaines, S.D. \& Lynham, J. (2008) Can catch shares prevent fisheries collapse? Science 321: 1678-1681.

Fisher, R.A. (1937) The wave of advance of advantageous genes. Annals of Eugenics 7: 353-369.

Forcada, A., Bayle-Sempere, J.T., Valle, C. \& Sanchez-Jerez, P. (2008) Habitat continuity effects on gradients of fish biomass across marine protected area boundaries. Marine Environmental Research 66(5): 536-547.

Forcada, A., Valle, C., Bonhomme, P., Criquet, G., Cadiou, G., Lenfant, P. \& Sanchez-Lizaso, J.L. (2009) Effects of habitat on spillover from marine protected areas to artisanal fisheries. Marine Ecology Progress Series 379: 197-211.

Francini-Filho, R.B. \& Moura, R.L. (2008) Evidence for spillover of reef fishes from a no-take marine reserve: an evaluation using the before-after control-impact (BACI) approach. Fisheries Research 93: 346-356.

Gell, F.R. \& Roberts, C.M. (2003) Benefits beyond boundaries: the fishery effects of marine reserves. Trends in Ecology and Evolution 18(9): 448-455.

Goni, R., Adlerstein, S., Alvarez-Berastegui, D., Forcada, A., Renones, O., Criquet, G., Polti, S., Cadiou, G., Valle, C., Lenfant, P., Bonhomme, P., Perez-Ruzafa, A., Sanchez-Lizaso, J.L., Garcia-Charton, J.A., Bernard, G., Stelzenmuller, V. \& Planes, S. (2008) Spillover from six western Mediterranean marine protected areas: evidence from artisanal fisheries. Marine EcologyProgress Series 366: 159-174.

Goni, R., Quetglas, A. \& Renones, O. (2006) Spillover of spiny lobsters Palinurus elephas from a marine reserve to an adjoining fishery. Marine Ecology Progress Series 308: 207-219.

Guenette, S., Pitcher, T.J. \& Walters, C.J. (2000) The potential of marine reserves for the management of northern cod in Newfoundland. In: Essential Fish Habitat and Marine Reserves, Bulletin of Marine Science Volume 66, ed. EDITORS, pp. 831852. Miami, FL, USA: University of Miami, Rosenthiel School of Marine and Atmospheric Science.

Guidetti, P. (2007) Potential of marine reserves to cause communitywide changes beyond their boundaries. Conservation Biology 21(2): $540-545$. 
Halpern, B.S. (2003) The impact of marine reserves: do reserves work and does reserve size matter? Ecological Applications 13(1): S117-S137.

Halpern, B.S., Gaines, S.D. \& Warner, R.R. (2004) Confounding effects of the export of production and the displacement of fishing effort from marine reserves. Ecological Applications 14(4): 12481256.

Halpern, B.S., Walbridge, S., Selkoe, K.A., Kappel, C.V., Micheli, F., D’Agrosa, C., Bruno, J., Casey, K.S., Ebert, C., Fox, H.E., Fujita, R., Heinemann, D., Lenihan, H.S., Madin, E.M.P., Myers, R., Perry, M., Selig, E., Spalding, M., Steneck, R. \& Watson, R. (2008) A global map of human impact on marine ecosystems. Science 319: 948-952.

Harmelin-Vivien, M., Le Direach, L., Bayle-Sempere, J., Charbonnel, E., Garcia-Charton, J.A., Ody, D., Perez-Ruzafa, A., Renones, O., Sanchez-Jerez, P. \& Valle, C. (2008) Gradients of abundance and biomass across reserve boundaries in six Mediterranean marine protected areas: evidence of fish spillover? Biological Conservation 141(7): 1829-1839.

Hastings, A. \& Botsford, L.W. (1999) Equivalence in yield from marine reserves and traditional fisheries management. Science 284(5419): 1537-1538.

Hilborn, R., Stokes, K., Maguire, J.J., Smith, T., Botsford, L.W., Mangel, M., Orensanz, J., Parma, A., Rice, J., Bell, J., Cochrane, K.L., Garcia, S., Hall, S.J., Kirkwood, G.P., Sainsbury, K., Stefansson, G. \& Walters, C. (2004) When can marine reserves improve fisheries management? Ocean and Coastal Management 47(3-4): 197-205.

Kaplan, D.M. \& Botsford, L.W. (2005) Effects of variability in spacing of coastal marine reserves on fisheries yield and sustainability. Canadian Fournal of Fish and Aquatic Science 62: 905-912 [www document]. URL http://www.escholarship. org/uc/item/75p6q8t0

Kaunda-Arara, B. \& Rose, G.A. (2004) Effects of marine reef national parks on fishery CPUE in coastal Kenya. Biological Conservation 118(1): 1-13.

Kellner, J.B., Nisbet, R.M. \& Gaines, S.D. (2008) Spillover from marine reserves related to mechanisms of population regulation. Theoretical Ecology 1: 117-127.

Kellner, J.B., Tetreault, I., Gaines, S.D. \& Nisbet, R.M. (2007) Fishing the line near marine reserves in single and multispecies fisheries. Ecological Applications 17(4): 1039-1054.

Kelly, S. \& MacDiarmid, A.B. (2003) Movement patterns of mature spiny lobsters, Fasus edwardsii, from a marine reserve. New Zealand Fournal of Marine and Freshwater Research 37(1): 149158.

Le Quesne, W.J.F. \& Codling, E.A. (2009) Managing mobile species with MPAs: the effects of mobility, larval dispersal, and fishing mortality on closure size. ICES Fournal of Marine Science 66(1): 122-131.

Lester, S.E., Halpern, B.S., Grorud-Colvert, K., Lubchenco, J., Ruttenberg, B.I., Gaines, S.D., Airame, S. \& Warner, R.R. (2009) Biological effects within no-take marine reserves: a global synthesis. Marine Ecology Progress Series 384: 33-46.

Lubchenco, J., Palumbi, S.R., Gaines, S.D. \& Andelman, S. (2003) Plugging a hole in the ocean: the emerging science of marine reserves. Ecological Applications 13: S3-S7.

McClanahan, T.R. \& Mangi, S. (2000) Spillover of exploitable fishes from a marine park and its effect on the adjacent fishery. Ecological Applications 10: 1792-1805.
McClanahan, T.R. \& Mangi, S. (2001) The effect of a closed area and beach seine exclusion on coral reef fish catches. Fisheries Management and Ecology 8(2): 107-121.

Micheli, F., Halpern, B.S., Botsford, L.W. \& Warner, R.R. (2004) Trajectories and correlates of community change in no-take marine reserves. Ecological Applications 14(6): 1709-1723.

Murawski, S.A., Wigley, S.E., Fogarty, M.J., Rago, P.J. \& Mountain, D.G. (2005) Effort distribution and catch patterns adjacent to temperate MPAs. ICES Fournal of Marine Science 62(6): 11501167.

Neubert, M.G. (2003) Marine reserves and optimal harvesting. Ecology Letters 6(9): 843-849.

Pauly, D., Christensen, V., Dalsgaard, J., Froese, R. \& Torres, F. (1998) Fishing down marine food webs. Science 279(5352): 860863.

Perez-Ruzafa, A., Martin, E., Marcos, C., Zamarro, J. M., Stobart, B., Harmelin-Vivien, M., Polti, S., Planes, S., Garcia-Charton, J. A. \& Gonzalez-Wanguemert, M. (2008) Modelling spatial and temporal scales for spill-over and biomass exportation from MPAs and their potential for fisheries enhancement. Fournal of Nature Conservation 16(4): 234-255.

Pitcher, T.J., Buchary, E.A. \& Hutton, T. (2002) Forecasting the benefits of no-take human-made reefs using spatial ecosystem simulation. ICES fournal of Marine Science 59: S17-S26 [www document]. URL http://icesjms.oxfordjournals. org/cgi/reprint/59/suppl/S17.pdf

R (2006) R: a Language and Environment for Statistical Computing. Vienna, Austria: R Development Core Team.

Rakitin, A. \& Kramer, D.L. (1996) Effect of a marine reserve on the distribution of coral reef fishes in Barbados. Marine Ecology Progress Series 131(1-3): 97-113.

Roberts, C.M., Bohnsack, J.A., Gell, F., Hawkins, J.P. \& Goodridge, R. (2001) Effects of marine reserves on adjacent fisheries. Science 294(5548): 1920-1923.

Roberts, C.M., Hawkins, J.P. \& Gell, F.R. (2005) The role of marine reserves in achieving sustainable fisheries. Philosophical Transactions of the Royal Society B. Biological Sciences 360(1453): 123-132.

Rodwell, L.D., Barbier, E.B., Roberts, C.M. \& McClanahan, T.R. (2003) The importance of habitat quality for marine reserve: fishery linkages. Canadian Fournal of Fisheries and Aquatic Sciences 60: $171-181$.

Rowley, R.J. (1994) Marine reserves in fisheries management. Aquatic Conservation, Marine and Freshmater Ecosystems 4(3): 233254.

Russ, G.R., Alcala, A.C., Maypa, A.P., Calumpong, H.P. \& White, A.T. (2004) Marine reserve benefits local fisheries. Ecological Applications 14(2): 597-606.

Samoilys, M.A. (1997) Movement in a large predatory fish: coral trout, Plectropomus leopardus (Pisces: Serranidae), on Heron Reef, Australia. Coral Reefs 16(3): 151-158.

Shigesada, N. \& Kawasaki, K. (1997) Biological Invasions: Theory and Practice. Oxford, UK: Oxford University Press.

Smith, M.D. \& Wilen, J.E. (2003) Economic impacts of marine reserves: the importance of spatial behavior. Fournal of Environmental Economics and Management 46: 183-206.

Topping, D.T., Lowe, C.G. \& Caselle, J.E. (2005) Home range and habitat utilization of adult California sheephead, Semicossyphus pulcher (Labridae), in a temperate no-take marine reserve. Marine Biology 147(2): 301-311. 
Tupper, M.H. (2002) Marine reserves and fisheries management. Science 295(5558): 1233-1233.

Williams, I.D., Walsh, W.J., Claisse, J.T., Tissot, B.N. \& Stamoulis, K.A. (2009) Impacts of a Hawaiian marine protected area network on the abundance and fishery sustainability of the yellow tang, Zebrasoma flavescens. Biological Conservation 142(5): 1066-1073.

Worm, B., Barbier, E.B., Beaumont, N., Duffy, J.E., Folke, C., Halpern, B.S., Jackson, J.B.C., Lotze, H. K., Micheli, F., Palumbi, S.R., Sala, E., Selkoe, K.A., Stachowicz, J.J. \& Watson, R. (2006)
Impacts of biodiversity loss on ocean ecosystem services. Science 314(5800): 787-790.

Zeller, D. \& Reinert, J. (2004) Modelling spatial closures and fishing effort restrictions in the Faroe Islands marine ecosystem. Ecological Modelling 172(2-4): 403-420.

Zeller, D., Stoute, S.L. \& Russ, G.R. (2003) Movements of reef fishes across marine reserve boundaries: effects of manipulating a density gradient. Marine Ecology Progress Series 254: 269280 . 